\title{
PENINGKATAN MOTORIK HALUS MELALUI KEGIATAN ORIGAMI PADA ANAK KELOMPOK A TK DWP KEDUNGRUKEM BENJENG GRESIK TAHUN PELAJARAN 2015/2016
}

\author{
NUR FAIZATIN \\ TK DWP Kedungrukem Kec. Benjeng Kab. Gresik \\ E-mail:piin.supiin@gmail.com
}

\begin{abstract}
ABSTRAK
Penelitian ini menggunakan Penelitian Tindakan Kelas (PTK) yang dilaksanakan dalam dua siklus, dengan masing-masing siklus terdapat perencanaan, pelaksanaan, observasi, dan refleksi. Sumber data adalah siswa Kelompok A TK DWP Kedungrukem Benjeng Gresik melalui kegiatan pembelajaran yang lebih menarik seperti melipat kertas dan melipat berbagai macam lipatan kertas. yang disesuaikan dengan tema sebagai sumber belajar terbukti mampu meningkatkan kemampuan melipat kertas pada anak, yaitu terlihat dari lembar data hasil pengamatan pada saat kegitan pembelajaran dengan melipat kertas yang berlangsung.

Hasil penelitian siklus I diperoleh hasil $57 \%$ peningkatan kemampuan melipat kertas dan pada siklus II diperoleh hasil 80\% peningkatan kemampuan melipat kertas, dengan hasil tersebut menujukkan bahwa penelitian ini berhasil karena telah mencapai target indikator penelitian sebesar $80 \%$.

Hasil penelitian ini menunjukkan bahwa dengan kegiatan melipat kertas (origami) sebagai sumber belajar dapat dikatakan berhasil dalam rangka meningkatkan keterampilan motorik halus anakanak. Berdasarkan penelitian tersebut disarankan pada semua guru dapat memberikan kegiatan melipat kertas/origami pembelajaran permulaan yang menarik dan menyenangkan anak. Guru juga hendaknya mampu menciptakan lingkungan pembela-jaran yang nyaman dan menyenangkan bagi anak.
\end{abstract}

\section{Kata kunci : Melipat kertas, Kreativitas dan berkarya seni}

\section{ABSTRACT}

This study uses Classroom Action Research (CAR) which is carried out in two cycles, with each cycle having planning, implementation, observation, and reflection. The data source is the students of Group A TK DWP Kedungrukem Benjeng Gresik through more interesting learning activities such as folding paper and folding various paper folds. which is adapted to the theme as a learning resource that is proven to be able to improve the ability to fold paper in children, which is seen from the observation data sheet during the learning activities by paper folding.

The results of the first cycle research showed that $57 \%$ increase in the ability to fold paper and in cycle II the results of $80 \%$ increase in the ability to fold paper were obtained, with these results showing that this study was successful because it had reached the target of the research indicator of $80 \%$.

The results of this study indicate that paper folding (origami) as a learning resource can be said to be successful in order to improve children's fine motor skills. Based on the research it is suggested that all teachers can provide paper folding / origami learning activities that are interesting and fun for children. Teachers should also be able to create a learning environment that is comfortable and fun for children.

Keywords: paper folding, creativity and art work

\section{PENDAHULUAN}

Pendekatan seni merupakan suatu proses pembelajaran yang dapat mening-katkan keterampilan motorik halus anak. Seni adalah kegiatan manusia dalam mengekspresikan pengalaman hidup dan kesadaran artistiknya yang melibatkan kemampuan intuisi, kepekaan indra dan rasa, kemampuan 
intelek-tual, kreatifitas serta keterampilan teknik untuk menciptakan karya yang memi-liki fungsi personal atau sosial dengan menggunakan berbagai media. Pengem-bangan seni juga bertu-juan mengembangkan keterampilan motorik halus anak didik dalam berolah tangan. Salah satu diantaranya adalah pembelajaran bidang seni rupa yaitu pada kegiatan melipat kertas (origami).

Melipat kertas (origami) merupakan kegiatan hiasan (ornamen) dengan menggunakan kertas tertentu. Origami peranannya bisa meluas ke segala bidang, misalnya dipergunakan sebagai bagian dari perlengkapan hidup. Origa-mi telah memasuki segala aspek kehidupan manusia. Dengan demikian origami memiliki peranan pada semua bidang tergantung pada kebutuhan manusia, termasuk peranannya dalam bidang pendidikan untuk keperluan melatih kemampuan motorik halus pada suatu pembelajaran.

$$
\text { Dalam meningkatkan }
$$

kemampuan motorik halus anak belum terencana secara khusus. Untuk itu sebaiknya masalah ini segera diantisipasi, sehingga kekhawatiran anak mengalami kesulitan dalam kemampuan motorik halus dapat diminimalisir. Pada umumnya motorik halus anak di Taman KakanKanak seba-gian besar terlambat tidak sesuai dengan usianya. Hal ini juga terlihat pada
TK DWP Kedungrukem Benjeng .

Secara khusus pada anak-anak Kelompok A TK DWP Kedungrukem Benjeng yang berusia 4-5 tahun belum dapat menggunakan alat tulis dengan baik dan benar, motorik halusnya sangat lemah/ kurang, terutama keterampilan melipat kertas. Anak-anak yang mengalami keterlambatan dalam perkem-bangan motorik halus, mengalami kesulitan untuk mengkoordinasikan gerak tangan dan jari jemarinya secara fleksibel, khususnya kegiatan melipat kertas (origami). Dari jumlah 38 anak didik, Kelompok A terdapat 30 atau sekitar $80 \%$ anak didik yang terlambat kemampuan motorik halusnya, sedangkan yang mampu hanya sebanyak 8 atau sekitar $20 \%$ anak didik.

Berdasarkan uraian diatas, penulis merasa tertarik untuk melakukan penelitian tentang kegiatan origami yang dapat dijadikan media pembelajaran untuk mempermudah meningkatkan keterampilan motorik halus. Penelitian tindakan kelas ini, berjudul "Peningkatan keterampilan motorik halus melalui kegiatan origami pada anak kelompok A TK DWP Kedungrukem Benjeng Gresik Tahun pelajaran 2015/2016"

Pengertian Motorik Halus menurut Moelichatoen (2004) adalah meru-pakan kegiatan yang menggunakan otot-otot halus pada jari dan tangan. Gera-kan ini keterampilan bergerak, sedangkan menu-rut 
Hurlock (1975) Moto-rik halus adalah gerakan yang menggunakan otot-otot halus atau sebagian ang-gota tubuh tertentu, yang dipengaruhi oleh kesem-patan untuk belajar dan berlatih. Menurut Susanto (2011) motorik halus adalaah gerak halus yang melibatkan bagian - bagian tertentu saja yang dilakukan oleh otototot kecil saja, Karena tidak memerlukan tenaga. Namun begitu gerak-kan yang halus ini memerlukan koordi-nasi yang cepat.

Menurut Nursalam (2005) Perkembangan motorik halus adalah kemam-puan anak untuk mengamati sesuatu dan melakukan gerakan yang melibatkan bagian-bagian tubuh tertentu dan otot-otot kecil, memerlukan koordinasi perkembangan motorik halus. Kemampuan motorik halus adalah kemampuan yang berhubungan dengan ketrampilan fisik yang melibatkan otak kecil dan koordinasi tangan-tangan. Saraf motorik halus ini dapat di latih dan di kembang-kan melalui kegiatan dan rangsangan yang kontinyu secara rutin. Seperti bermain puzzle, menyusun balok, memasukkan benda ke dalam lubang sesuai bentuknya, membuat garis, melipat kertas dan sebagainya.

Berdasarkan teori tersebut di atas, dapat disimpulkan bahwa perkembangan motorik halus adalah kemampuan gerak keterampilan fisik seseorang berdasarkan koordinasi otak kecil, dan otot-otot halus jari dan tangan yang dipengaruhi oleh belajar dan berlatih.

Menurut M. Amanuma dalam Danandjaja (1997 :297), Origami adalah seni melipat kertas menjadi berbagai bentuk. Bangsa Jepang tidak menganggap origami sebagai suatu seni yang berdiri sendiri, karena mereka lebih menganggap melipat kertas itu sebagai satu bagian yang tak terpisahkan dengan kebudayaan bangsanya. Bahan yang digunakan origami adalah kertas atau kain yang biasanya berbentuk persegi. Sebuah hasil origami merupakan suatu hasil kerja tangan yang sangat teliti dan enak dipandang.

Origami adalah sebagai seni membuat objek, rata- rata yang digunakan adalah selembar kertas. Origami merupakan seni tradisional melipat kertas yang berkembang menjadi suatu bentuk kesenian modern.

Maka dapat disimpulkan bahwa origami adalah seni melipat kertas atau kain dalam berbagai bentuk, dari hasil kerja tangan yang sangat teliti dan halus, enak dipandang, dimana merupakan seni Dari Cina, terus ke Spanyol, untuk selanjutnya berkembang ke Jepang dan menjadi seni tradisional Jepang yang berkembang menjadi seni modern yang diakui dan dinikmati secara universal

\section{METODE PENELITIAN}

Penelitian ini menggunakan penelitian tindakan kelas (PTK) yakni penelitian praktis yang 
bertujuan untuk memperbaiki kekurangan-kekurangan dalam pembelajaran dikelas dengan cara melakukan tindakan-tindakan. Upaya tindakan memperbaiki dan meningkatkan perlu adanya praktekpratek pembela-jaran dikelas secara lebih profesional. Oleh karena itu PTK terkait erat dengan untuk memperbaiki dimaksudkan sebagai pencarian jawaban atas permasalahan yang diungkap dan dicarikan jalan keluar dalam penelitian adalah yang benar-benar ada dan dialami oleh guru (Suyanto: 1997,4)

Prosedur penelitian tindakan kelas merupakan proses pengkajian melalui sistem berdaur dari berbagai kegiatan pembelajaran, menurut Raka

Joni (1988), terdapat lima tahapan, yaitu :

1. Pengembangan fokus masalah peneli-tian.

2. Perencanaan tindakan perbaikan.

3. Pelaksanaan tindakan perbaikan, ob-servasi dan interpretasi.

4. Analisis dan refleksi.

5. Perencanaan tindak lanjut.

Penelitian tindakan kelas (PTK) yang dilaksanakan secara kolaborasi antara guru dan pihakpihak lain yang bertujuan untuk meningkatkan kinerja guru serta hasil belajar anak. Dengan kata lain, PTK bertujuan bukan hanya berusaha mengungkapkan penyebab dari berbagai permasalahan pembelajaran yang dihadapi, misalnya kesulitan siswa dalam memahami pokok-pokok bahasan tertentu, tetapi yang lebih penting lagi adalah memberiksn solusi berupa tinda-kan untuk mengatasi permasalahan pem-belajaran tersebut (Subyantoro : 2009, 27).

Penulis akan melaksanakan prose-dur penelitian tindakan kelas dengan menggunakan dua siklus. Setiap siklus memiliki empat tahap yaitu (1) Perenca-naan, Pelaksanaan, (3) Pengamatan, dan (4) Refleksi (Subyantoro : 2009, 27)

\section{HASIL}

Hasil pada proses pembelajaran sebelum diberi-kan tindakan menunjukkan bahwa indikator dapat meniru 3 lipatan kertas menjadi bentuk ikan $43 \%$ anak mampu meniru 5 lipatan menjadi keranjang $39 \%$ anak mampu meniru 6 lipatan menjadi bentuk tulip $34 \%$ anak mampu membuat lipatan kertas menjadi burung $26 \%$ anak dapat membuat hiasan dari kertas lipat $30 \%$ anak membuat coretan dalam lipa-tan kertas dengan cat air 34\% anak dapat menggambar pohon kemudian diberi hiasan bunga dan burung dari hasil origami kemudian diwarnai $30 \%$ anak melipat bentuk rumah kemudian ditambah dengan hiasan taman bunga dan kupu-kupu $26 \%$ 


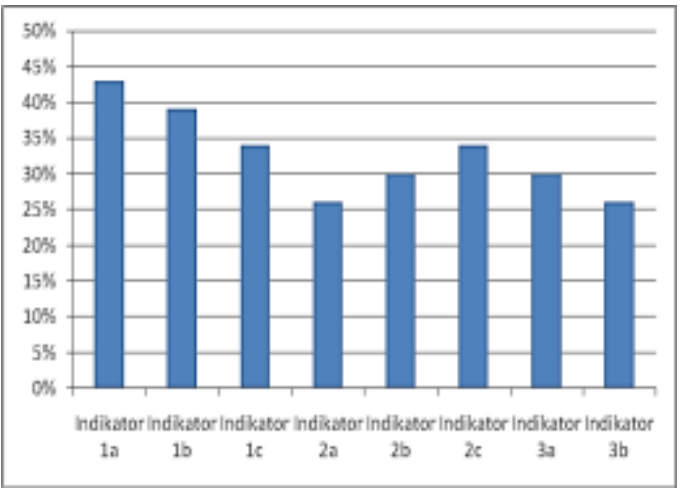

Grafik1. Presentase Hasil Sebelum

Siklus

\section{Hasil Penelitian Siklus I}

Pada penelitian siklus I, ada 3 indi-kator yang diamati dengan ratarata hasil sebagai berikut: indikator dapat meniru 3 lipatan kertas menjadi ikan $56 \%$ meniru 5 lipatan menjadi bentuk keran-jang $60 \%$ meniru 6 lipatan menjadi bunga tulip $60 \%$ membuat lipatan kertas menjadi burung $56 \%$ membuat hiasan dari kertas lipat 52\% membuat coretan dalam lipatan kertas dengan cat air 56\% menggambar pohon kemudian diberi hiasan bunga dan burung dari hasil origami $56 \%$ melipat bentuk rumah kemudian ditambah dengan hiasan tanaman bunga dan kupu-kupu $60 \%$.

Bila ditinjau dari sebelum tindakan dan setelah adanya tindakan untuk siklus I terdapat peningkatan untuk anak. Pada indikator anak mampu melipat kertas dengan sempurna dan dapat mengkrea-sikan lipatan dengan gambar yang dibuatnya sendiri atau pun penambahan gambar pada lipatan tersebut. mengalami perkem-bangan.

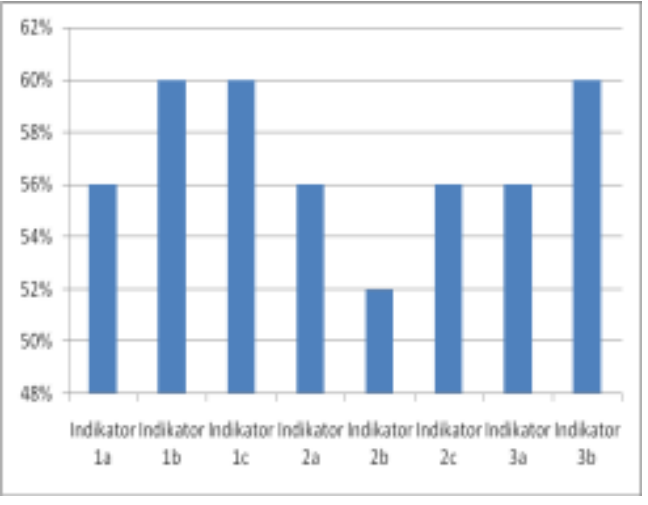

Grafik 2. Persentase Hasil Siklus 1

\section{Hasil penelitian siklus II}

Pada penelitian siklus II, ada 3 indikator yang diamati dengan ratarata hasil sebagai berikut: indikator dapat menunjukkan anak dapat meniru 3 lipatan kertas menjadi bentuk ikan $86 \%$ anak mampu meniru 5 lipatan kertas menjadi bentuk keranjang $82 \%$ anak mampu meniru 6 lipatan menjadi bentuk tulip $78 \%$ anak mampu membuat lipatan kertas menjadi burung $78 \%$ anak dapat membuat hiasan dari kertas lipat $86 \%$ anak membuat coretan dalam lipatan kertas dengan cat air $91 \%$ anak dapat menggambar pohon kemudian diberi hiassan bunga dan burung dari hasil origami kemudian diwarnai $65 \%$ anak melipat bentuk rumah kemudian ditambah dengan hiasan taman bunga dan kupu-kupu 78\%

$$
\text { Pada proses pembelajaran }
$$

siklus 2, ketika tahap pendahuluan pembe-lajaran melalui kegiatan melipat kertas anak-anak sudah menunjukkan ketertarikannya. Apalagi ketika anak-anak mencoba membuat sendiri berkreasi dengan 
mengunakan crayon, cat air dan hiasan yang mereka buat sendiri anak lebih senang membuatnya. Hal ini menunjukkan bahwa siswa termotivasi untuk dapat meningkatkan pemahaman tentang melipat kertas dengan mengikuti kegiatan melipat kertas dengan yang dilaksanakan selama pembelajaran.

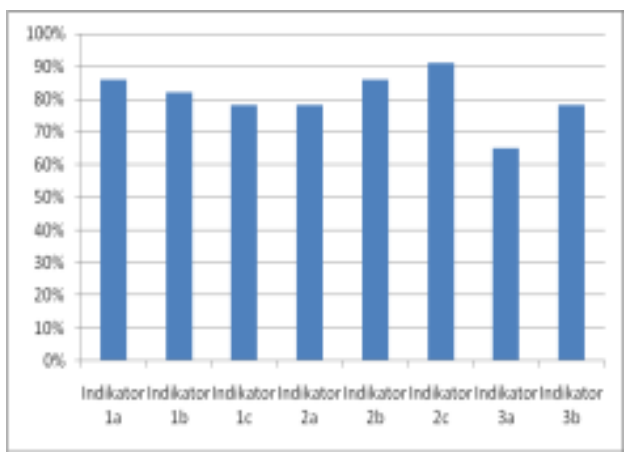

Grafik 3. Persentase Hasil Siklus 2

\section{PEMBAHASAN}

Banyak anak yang sudah mampu meningkatkan keterampilan moto-rik halus dalam dirinya. Imajinasi anak berkembang ketika anak diberikan kebebasan untuk menciptakan sesuatu yang berbeda dari yang lainnya. Keterampilan tersebut dituangkan melalui kegiatan melipat kertas yang mengasyikkan untuk anak, guru dapat mengembangkan kegiatan belajar melipat untuk anak, agar meningkatkan keterampilan anak supaya anak merasa senang dan nyaman saat melakukan kegiatan sehingga potensi anak dapat berkembang sesuai tahapannya.

Keterampilan merupakan sesuatu proses, bukan hasil. Keterampilan merupakan hasil belajar yang terus menerus, yang memerlukan bimbingan terus menerus tanpa henti hentinya dan tanpa bosan.

\section{HASIL PENGAMATAN PRA SIKLUS, SIKLUS I DAN SIKLUS} II

\begin{tabular}{|c|c|c|c|c|}
\hline $\begin{array}{c}\text { Indika } \\
\text { tor }\end{array}$ & Sub Indikator & $\begin{array}{c}\text { Pra } \\
\text { Siklu } \\
\text { s }\end{array}$ & $\underset{1}{\text { Siklus }}$ & $\begin{array}{c}\text { Siklu } \\
\text { s II }\end{array}$ \\
\hline $\begin{array}{l}\text { 1.Men } \\
\text { iru } \\
\text { me } \\
\text { mbu } \\
\text { at } \\
\text { lipat } \\
\text { an }\end{array}$ & $\begin{array}{ll}\text { a. } & \text { Anak dapat } \\
& \text { meniru } 3 \\
& \text { lipatan kertas } \\
& \text { menja-di } \\
& \text { bentuk ikan } \\
\text { b. } & \text { Anak dapat } \\
& \text { meniru } 5 \\
\text { lipatan kertas } & \text { menja-di } \\
\text { bentuk } & \text { keranjang } \\
\text { c. Anak dapat } \\
\text { meniru } 3 \\
\text { lipatan kertas } \\
\text { menja-di } \\
\text { bentuk ikan }\end{array}$ & $39 \%$ & $60 \%$ & $82 \%$ \\
\hline $\begin{array}{l}\text { 2.Ber } \\
\text { krea } \\
\text { tifita } \\
\text { s } \\
\text { den } \\
\text { gan } \\
\text { lipat } \\
\text { an }\end{array}$ & 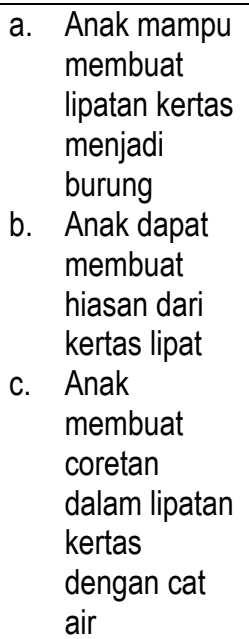 & $20 \%$ & $52 \%$ & $78 \%$ \\
\hline
\end{tabular}




\begin{tabular}{|c|c|c|c|c|}
\hline $\begin{array}{l}3 . \\
\text { elaj } \\
\text { ar } \\
\text { kary } \\
\text { a } \\
\text { seni }\end{array}$ & $\begin{array}{l}\text { a. Anak dapat } \\
\text { menggambar } \\
\text { pohon } \\
\text { kemudian } \\
\text { diberinhiasan } \\
\text { bungah dan } \\
\text { burung dari } \\
\text { hasil origami } \\
\text { kemudian di } \\
\text { warnai } \\
\text { b. Anak melipat } \\
\text { bentuk rumah } \\
\text { kemussdian } \\
\text { di tambah } \\
\text { hiasan taman } \\
\text { bungah dan } \\
\text { kupu-kupu }\end{array}$ & $30 \%$ & $56 \%$ & $65 \%$ \\
\hline \multicolumn{2}{|c|}{$\begin{array}{l}\text { Persentase rata-rata } \\
\text { peningkatan kemampuan } \\
\text { melipat ketas pada anak }\end{array}$} & $32 \%$ & $57 \%$ & $80 \%$ \\
\hline \multicolumn{2}{|c|}{ Keterangan } & - & $\begin{array}{l}\text { belum } \\
\text { tercap } \\
\text { ai }\end{array}$ & $\begin{array}{l}\text { suda } \\
\text { h } \\
\text { terca } \\
\text { pai }\end{array}$ \\
\hline
\end{tabular}

\section{SIMPULAN}

Dari uraian penelitian ini dapat diambil kesimpulan sebagai berikut: bahwa dengan kegiatan melipat kertas atau origami kita dapat melatih motorik halus anak agar anak lebih terampil membuat lipatan dan bentuk yang dicontoh kan oleh guru, anak juga dapat membuat lipatan sendiri dengan lipatan yang lain.

Kegiatan melipat kertas ini juga dapat dikembangkan dengan berbagai macam bentuk dan dapat juga diberi hiasan yang lain misalnya : menggambar yang ditambah dengan lipatan burung dan bunga serta diberi warna yang menarik dan sesuai. Anak juga dapat memberikan coretan dengan cat air pada kertas lipat tersebut. Dengan begitu keterampilan yang dipunyai anak keluar dengan sendirinya. Selain itu juga anak dan guru sesering mungkin mengajar-kan anak didiknya untuk berlatih melipat agar lebih terampil dalam melipat kertas membuat origami.

Guru juga harus dapat menciptakan suasana yang nyaman dan menye-nangkan untuk anak. Agar dalam kegiatan melipat anak tidak bosan, guru memberikan cerita kepada anak dari hasil lipatan yang anak buat sendiri. .

\section{SARAN}

Berdasarkan kesimpulan tersebut, saran yang diberikan untuk mening-katkan pemahaman tentang melipat kertas pada anak melalui kegiatan mem-bentuk kreasi lipatan adalah :

a. Bagi guru selaku pendidik agar lebih kreatif dan bervariasi lagi untuk membuat suatu origami, supaya anak juga dapat berkreasi sesuai dengan imajinasi anak itu sendiri. Dengan adanya ketertarikan untuk berkreasi dengan lipatan kertas yang menarik, enak dipadang, dengan bahan kertas yang berwarna warni, anak akan tertarik dan ingin mem-buat sendiri yang berbeda. Guru juga terus memotivasi anak untuk selalu berkreasi dan berimajinasi melipat kertas yang lebih baik. 
b. Bagi sekolah, hendaknya lebih memfasilitasi lagi untuk kegiatan melipat kertas, membentuk kreasi lipatan kertas, meningkatkan keterampilan pada anak, menyediakan sarana dan prasarana yang lengkap.

c. Bagi orang tua, hendaknya memberikan fasilitas yang memadai sehingga belajar dan mengajar tentang origami dapat berjalan dengan lancar.

\section{DAFTARPUSTAKA}

Arikunto, suharsimi, 2010. Prosedur Penelitian Suatu Pendekatan Praktik. Jakarta : PT Rineka Cipta

Dr. Andyda Melia, 2011. Jurnal Nasional

Eqtada A.Bilhaque, 2013, ModelModel Menarik Origami, Penerbit Plus Multimedia

Hurlock Elizzabeth B, (1992). Developmental psychology. Jakarta: Penerbit Erlangga

Hurlock Elizzabeth B., 1992, Psikologi Perkembangan Anak, Jilid 1-2. Jakarta : Penerbit Erlangga

M. Amanuma, (1997:297). Seni Melipat Kertas dari Negeri Sakura

Makiko Ikeda \& Kris Hirschmann, 2009 Origami Seni Lipat Kertas, Penerbit Dahar Prize

Muslich, Masnur, 2011. Melaksanakan PTK Penelitian Tindakan Kelas Itu Mudah.Jakarta : PT Bumi Aksara

Nur Anisah, 2009. Mahir Membuat Origami Bentuk Binatang: Buku kita com.
Robeert J.Lang, 2006. The Fourth Internasional Meeting On Origami In Science (40 SME)

Saifuddin, Azwar, 1998. Metode Penelitian. Yogyakarta : Pustaka pelajar

Standar Tingkat Pencapaian perkembangan Anak Usia Dini. Permen No.58 Tahun 2009

Sugiyono, 2010. Metode Penelitian Pendidikan. Bandung : Alfabeta

Sukardi, 2008, Metodologi Penelitian Pendidikan: Kompetensi dan Prakteknya

Sukmadinata, N, Syaodih, 2009. Metode Penelitian Pendidikan. Bandung : PT Remaja Rosdakarya

Tahir Hadi, 2012, Origami Hewan Kreasi Baru Yang Menawan. Jakarta : PT Gramedia Pustaka Utam 
Peningkatan Motorik Halus Melalui Kegiatan Origami Pada Anak Kelompok A Tk Dwp Kedungrukem Benjenggresik

Tahun Pelajaran 2015/2016 